\title{
Balanço Eletrolítico e Níveis de Proteína Bruta sobre Parâmetros Sanguiíneos e Ósseos de Frangos de Corte aos 21 Dias de Idade ${ }^{1}$
}

\section{Flávio Medeiros Vieites ${ }^{2}$, George Henrique Kling de Moraes $^{3}$, Luiz Fernando Teixeira Albino ${ }^{4}$, Horacio Santiago Rostagno ${ }^{4}$, Ana Cláudia Rodrigues ${ }^{5}$, Fernanda Álvares da Silva ${ }^{6}$, Anel Atencio ${ }^{7}$}

\begin{abstract}
RESUMO - Foi realizado um experimento com o objetivo de determinar os melhores valores de balanço eletrolítico (BE) para frangos de corte de 1 a 21 dias. Utilizaram-se 2.112 pintinhos da marca comercial Ross, machos, criados em boxes de galpão de alvenaria, cobertos com maravalha e alimentados com duas rações basais, uma com 20 e outra com $23 \%$ de proteína bruta (PB) à base de milho e de farelo de soja, combinadas com níveis de BE de 00; 50;100;150;200; 250; 300 e 350 mq/kg. Foi utilizado delineamento experimental inteiramente casualizado, em esquema fatorial 8x2 (oito níveis de BE e dois níveis de PB), seis repetições e 22 aves por unidade experimental. Avaliaram-se os níveis sangüíneos de cálcio, fósforo e proteínas totais aos 21 dias de idade. As cinzas, o cálcio, o fósforo, o potássio, o sódio e o magnésio dos ossos também foram quantificados. Aos 21 dias de idade, os melhores valores estimados de BE foram $168(20 \% \mathrm{~PB})$ e $245(23 \% \mathrm{~PB}) \mathrm{mEq} / \mathrm{kg}$ para o cálcio no sangue. O valor de BE obtido para o menor nível de proteínas totais foi de 189 (23\% PB) $\mathrm{mEq} / \mathrm{kg}$. Os melhores valores de BE no sangue foram os pontos de mínimo na curva de regressão. O melhor valor de BE para o cálcio no tibiotarso foi de $132 \mathrm{mEq} / \mathrm{kg}$ (23\% PB). O BE da dieta deve situar-se entre 150 e $200 \mathrm{mEq} / \mathrm{kg}$ para frangos de corte de 1 a 21 dias de idade.
\end{abstract}

Palavras-chave: cálcio, equilíbrio ácido-básico, fósforo, frangos de corte, osso, sangue

\section{Electrolyte Balance and Crude Protein Levels on Blood and Bone Parameters of 21 Days Broiler Chicks}

\begin{abstract}
An experiment was conducted to determine the best electrolyte balance (EB) for broiler chicks from one to 21 days of age, based on blood and bone parameters. One day old chicks, male, Ross were reared on floor covered with shaving woods and fed with two corn-soybean meal based diet with 20 and $23 \%$ of crude protein $(\mathrm{CP})$ combined with $0 ; 50 ; 100 ; 150 ; 200 ; 250 ; 300$ and 350 $\mathrm{mEq} / \mathrm{kg}$ of EB. The experiment was analised as a completely randomized design in a factorial arrangement of treatments (two CP levels and eight EB) with six replicates of 22 chicks each. It were evaluated blood levels of calcium, phosphorus and total proteins. Ash, calcium, phosphorus, potassium, sodium and magnesium in the bone were also measured at 21 days of age. The best values of EB estimated were $168(20 \% \mathrm{CP})$ and $245(23 \% \mathrm{CP}) \mathrm{mEq} / \mathrm{kg}$ for blood calcium. The EB value obtained for the lowest level of blood total protein was 189 $(23 \% \mathrm{CP}) \mathrm{mEq} / \mathrm{kg}$. The optimum EB obtained in the blood were the minimum points of the regression curve. The best value for calcium in the bone was $132 \mathrm{mEq} / \mathrm{kg}$ (23\% CP). The dietary EB should be from 150 to $200 \mathrm{mEq} / \mathrm{kg}$, concerning the biological responses of broiler chicks (from 1 to 21 days of age).
\end{abstract}

Key Words: acid basic balance, broiler chicks, calcium, phosphorus, bone, blood

\section{Introdução}

Pesquisas têm mostrado que a composição mineral da ração afeta o equilíbrio ácido-básico e vários aspectos do desempenho animal (Murakami, 2000). A manutenção do equilíbrio ácido-básico do meio interno tem grande importância fisiológica e bioquímica, uma vez que as atividades das enzimas celulares, trocas eletrolíticas e manutenção do estado estrutural das proteínas dos organismos são profundamente influenciadas por pequenas alterações no pH sangüíneo (Macari, 1994).

O equilíbrio ácido-básico está diretamente ligado aos eletrólitos ingeridos pelas aves. O balanço

\footnotetext{
${ }^{1}$ Parte da tese de Doutorado apresentado pelo primeiro autor à UFV.

2 Médico Veterinário, D.S. em Nutrição de Monogástricos. E.mail: fmvieites@yahoo.com.br

3 Professor do DBB/ UFV, Campus Universitário - Viçosa MG, Brasil. CEP: 36571-000

${ }^{4}$ Professor do DZO/ UFV, Campus Universitário - Viçosa MG, Brasil. CEP: 36571-000

5 Professora do DPTo Bioq/UFJF. E.mail: rodrigues@ICB.ufjf.br

6 Técnica/Pesquisadora do CGEN - MMA, CEP 70800-200, Brasília, DF

${ }^{7}$ Médico Veterinário, DSc em Nutrição de Monogástricos. E.mail: anel@arches.uga.edu
} 
eletrolítico (BE) pode influenciar o crescimento, o apetite, o desenvolvimento ósseo, a resposta ao estresse térmico e o metabolismo de certos nutrientes, como aminoácidos, minerais e vitaminas (Patience, 1990).

Os principais elementos envolvidos nesse equilíbrio são os cátions sódio $\left(\mathrm{Na}^{+}\right)$, potássio $\left(\mathrm{K}^{+}\right)$e magnésio $\left(\mathrm{Mg}^{++}\right)$, os ânions cloro $\left(\mathrm{Cl}^{-}\right)$, bicarbonato $\left(\mathrm{HCO}_{3}^{-}\right) \mathrm{e}$ fosfato dibásico $\left(\mathrm{H}_{2} \mathrm{PO}_{4}^{-}\right)$, além de algumas proteínas. $\mathrm{O} \mathrm{Na}{ }^{+}$e o $\mathrm{Cl}^{-}$contribuem sobretudo para a pressão osmótica do plasma, enquanto o $\mathrm{Mg}^{++}$, os fosfatos e as proteínas, para pressão osmótica do fluido intracelular (González \& Silva, 1999).

Muitos estudos têm sido direcionados ao desenvolvimento de expressões simplificadas de BE, de forma a identificar a relação crítica de eletrólitos para o uso em formulações de rações. Mongin (1981) utilizou a seguinte fórmula para compor a ingestão mineral e o equilíbrio ácido-básico do animal:

\section{$\mathrm{BE}, \mathrm{mEq} / \mathrm{kg}$ da ração $=\left(\mathrm{mg} / \mathrm{kg}\right.$ de $\mathrm{Na}^{+}$da ração/ $22,990)+\left(\mathrm{mg} / \mathrm{kg}\right.$ de $\mathrm{K}^{+}$da ração /39,102 $)-$ $\left(\mathrm{mg} / \mathrm{kg}\right.$ de $\mathrm{Cl}^{-}$da ração/35,453)}

Mongin (1981) determinou que, para frangos de corte, devem ser utilizados simultaneamente BE de $250 \mathrm{mEq} / \mathrm{kg}$ e relação $\left(\mathrm{K}^{+}+\mathrm{Cl}^{-}\right) / \mathrm{Na}^{+}$maior que 1 (um). Segundo esse autor, Sauver \& Mongin (1974), citados por Mongin (1981), verificaram que as aves toleravam mais o excesso de $\mathrm{K}^{+}$que de $\mathrm{Na}^{+}$.

Entretanto, Dari (2002) afirma que o BE das rações normalmente utilizadas, na prática, para frangos de corte varia de 150 a $230 \mathrm{mEq} / \mathrm{kg}$, similar ao trabalho de Teeter (1997), em que o BE foi de 201 e $182 \mathrm{mEq} / \mathrm{kg}$, para as fases inicial e crescimento, respectivamente.

O sangue de um animal transporta nutrientes do trato digestivo para os tecidos, os produtos finais do metabolismo das células até os órgãos de excreção, o oxigênio dos pulmões para os tecidos, o dióxido de carbono dos tecidos para os pulmões e as secreções das glândulas endócrinas por todo o corpo. O sangue também ajuda a regular a temperatura corporal, mantém constante a concentração de água e de eletrólitos nas células, regula a concentração de íon hidrogênio no corpo e defende-o contra microorganismos. As células do sangue e compartimentos líquidos do corpo ajudam nessas funções (Swenson, 1996).

Os constituintes extracelulares do sangue incluem a água, os eletrólitos, as proteínas, a glicose, as enzimas e os hormônios. Entre os eletrólitos merecem destaque o cálcio ionizável e o fosfato. As proteínas no soro também são essenciais para a manutenção da homeostasia.

O cálcio é essencial para a coagulação sangüínea, permeabilidade de membrana, excitabilidade neuromuscular, transmissão do impulso nervoso e ativação de sistemas enzimáticos. Deficiência ou excesso de cálcio pode reduzir a atividade cardíaca por meio do aumento da duração e da força de contração do músculo cardíaco.

O fósforo une-se ao cálcio e ao carbonato formando compostos que conferem rigidez aos ossos. Participa do metabolismo energético, metabolismo de carboidratos, aminoácidos e gordura, nos processos químicos do sangue, crescimento do esqueleto, transporte de ácidos graxos e outros lipídios. Participa também como constituinte de ácidos nucléicos, e componentes de muitas coenzimas, além de estar envolvido no armazenamento e transferência de energia em compostos fosforilados da glicose e seus derivados (McDowell, 1992).

As proteínas plasmáticas são responsáveis pela manutenção da pressão coloidosmótica do plasma, contribuindo para que a pressão sangüínea se mantenha dentro dos limites normais. Além disso, ajudam a regular o equilíbrio ácido-básico do sangue e participam do transporte de nutrientes $(\mathrm{Ca}, \mathrm{P}, \mathrm{Fe}$, $\mathrm{Cu}$, lipídios, vitaminas lipossolúveis, aminoácidos), hormônios, colesterol, bilirrubina e outras substâncias (Swenson, 1996).

O osso é uma forma especializada de tecido conjuntivo, constituído por células e por matriz extracelular. A característica que o distingue dos demais tecidos orgânicos é a mineralização da matriz, o que produz um tecido extremamente rígido, capaz de desempenhar funções de sustentação e proteção (Ross \& Rowrell, 1993).

O desequilíbrio de cátions e de ânions na ração pode ter influência na incidência de problemas de pernas em pintos. Tardin (1995) relata que alto teor de cloro tende a aumentar a incidência de discondroplasia da tíbia, sobretudo quando os níveis de sódio e de potássio são baixos. Se os níveis de sódio e de cloro são baixos, os teores de cinza nos ossos decrescem. Hulan (1987), citado por Edwards (1992), constatou significativa interação entre sódio, potássio e cloro no desenvolvimento da discondroplasia na tíbia e os resultados eram sempre melhores quando o nível de cloro era reduzido e o de sódio, elevado. Há

R. Bras. Zootec., v.33, n.6, p.1520-1530, 2004 
evidências de que acidose metabólica induzida por níveis altos de cloro pode reduzir a formação de 1,25 $(\mathrm{OH})_{2} \mathrm{D}_{3}$ (Mongin \& Sauveur, 1977) e, consequientemente, problemas locomotores podem aparecer.

Summers et al. (1984) relataram que os problemas de pernas decorrem de situações complexas que envolvem interrelações entre diversos nutrientes. Ao avaliar níveis energéticos e protéicos na dieta de frangos de corte, Sauveur (1984) concluiu que altos níveis de energia e proteína podem contribuir para aumento na incidência de problemas de perna, sem necessariamente afetar a velocidade de crescimento. Entretanto, tais dietas são, geralmente, usadas para maximizar a eficiência alimentar.

Heaney (1998), estudando o nível protéico e o metabolismo ósseo em humanos, verificou que dietas com altos níveis protéicos acarretam aumento na excreção urinária de cálcio, diminuindo os níveis séricos desse mineral. Outro nutriente associado à redução da massa óssea, quando em excesso no sangue, é o sódio, por também aumentar a excreção de cálcio via urina.

Objetivou-se, neste trabalho, determinar o melhor valor de BE em rações com dois níveis de proteína bruta para frangos de corte de 21 dias de idade com base nos parâmetros sangüíneos e ósseos.

\section{Material e Métodos}

O presente trabalho foi conduzido no setor de avicultura do Departamento de Zootecnia da Universidade Federal de Viçosa, no período de outubro a novembro de 2001.

Foram utilizados 2.112 pintos da marca comercial Ross, machos, alojados em galpão de alvenaria, com pé direito de 3,0 m, cobertura com telhas de cimento amianto, provido de lanternim, mureta com laterais de $0,50 \mathrm{~m}$, tela de $1 / 2$ '. Foram utilizados boxes de $1,25 \mathrm{x}$ $1,80 \mathrm{~m}\left(2,25 \mathrm{~m}^{2}\right)$ com piso de cimento. No piso de cada boxe, foi colocada maravalha como cama (altura de $10 \mathrm{~cm}$ ).

As aves que morreram até o quinto dia foram substituídas por outras que estavam sendo mantidas em boxes extras, sendo estas criadas nas mesmas condições de manejo das aves em experimento.

Durante o período experimental, foi adotado programa de luz contínuo (24 horas de luz natural + artificial). Para aquecimento das aves do $1 \underline{\mathrm{o}}$ ao $15 \underline{\mathrm{o}}$ dia, foram utilizadas lâmpadas infravermelhas de
250W, com altura regulável.

As variáveis ambientais, temperatura e umidade relativa do ar foram medidas com termômetros de máxima e mínima, termômetro de bulbo seco e úmido e termômetro de globo negro para obtenção do ITGU (Índice de Temperatura de Globo e Umidade). A temperatura do galpão foi registrada diariamente e as leituras foram feitas às 7 e $19 \mathrm{~h}$ por termômetros de máxima e mínima, sendo 20 e $30^{\circ} \mathrm{C}$ as médias das temperaturas máximas e mínimas, respectivamente, para o período experimental. As leituras dos termômetros das demais variáveis foram realizadas cinco vezes ao dia $(7,10,13,16$ e $19 \mathrm{~h})$, e suas médias corresponderam a $66 \%$ para a umidade relativa do are $74 \%$ para o ITGU.

Foram utilizadas duas rações basais, formuladas à base de milho, de farelo de soja e de farelo de glúten de milho, contendo 20 e $23 \%$ de proteína bruta (PB), de forma a atender às recomendações nutricionais segundo Rostagno (2000), exceto cloro e potássio para a fase de 1 a 21 dias. Essas rações foram formuladas de forma a conter $\mathrm{BE}$ de $150 \mathrm{mEq} / \mathrm{kg}$, aproximadamente, sendo utilizado como fonte de cloro o cloreto de amônia (Tabela 1).

Os valores de BE foram calculados utilizando a seguinte fórmula sugerida por Mongin (1981):

$$
\begin{gathered}
\mathrm{BE}, \mathrm{mEq} / \mathrm{kg} \text { da ração }=\left(\mathrm{mg} / \mathrm{kg} \text { de } \mathrm{Na}^{+}\right. \text {da ração/ } \\
22,990)+\left(\mathrm{mg} / \mathrm{kg} \text { de } \mathrm{K}^{+} \text {da ração } / 39,102\right)- \\
\left(\mathrm{mg} / \mathrm{kg} \mathrm{de} \mathrm{Cl}^{-}\right. \text {da ração/35,453) }
\end{gathered}
$$

Foi utilizado delineamento experimental inteiramente casualizado, em esquema fatorial $8 \times 2$ (oito níveis de $\mathrm{BE}$ dentro de dois níveis de $\mathrm{PB}$ ), seis repetições e 22 aves por unidade experimental. Cada ração basal ( 20 e $23 \%$ de $\mathrm{PB}$ ) foi suplementada com cloreto de amônia $\left(\mathrm{NH}_{4} \mathrm{Cl}\right)$ ou carbonato de potássio $\left(\mathrm{K}_{2} \mathrm{CO}_{3}\right)$, em substituição ao material inerte, de forma a obter oito níveis de BE: 0; 50; 100; 150; 200; 250; 300 e $350 \mathrm{mEq} / \mathrm{kg}$. O cloreto de amônia $\left(\mathrm{NH}_{4} \mathrm{Cl}\right)$ foi utilizado para se obter os balanços de 0,50 e $100 \mathrm{mEq} / \mathrm{kg}$ e o carbonato de potássio $\left(\mathrm{K}_{2} \mathrm{CO}_{3}\right)$, para balanços de 200, 250, 300 e $350 \mathrm{mEq} / \mathrm{kg}$. Os tratamentos experimentais podem ser observados na Tabela 2 e os níveis de sódio, potássio e cloro obtidos em cada ração experimental, na Tabela 3. As aves foram distribuídas uniformemente com um dia de idade e peso médio de $45 \mathrm{~g}$.

O soro sangüíneo de uma ave com peso médio de cada unidade experimental foi coletado por punção cardíaca no 21 o dia de idade. O sangue foi colocado 
Tabela 1 - Composição percentual e valores nutricionais calculados das rações experimentais

Table 1 - Percentage composition and calculated nutritional values of the experimental diets

\begin{tabular}{|c|c|c|c|c|c|c|}
\hline $\begin{array}{l}\text { Ingredientes } \\
\text { Ingredients }\end{array}$ & $\begin{array}{c}\text { Ração } 20 \% \\
\text { Diet } 20 \% \\
\end{array}$ & $\begin{array}{c}\text { Ração } 23 \% \\
\text { Diet } 23 \% \\
\end{array}$ & $\begin{array}{l}\text { Antioxidante } \\
\text { Antioxidant }\end{array}$ & \multicolumn{2}{|c|}{0,010} & 0,010 \\
\hline $\begin{array}{l}\text { Milho } \\
\text { Corn }\end{array}$ & 60,870 & 55,913 & $\begin{array}{l}\text { Inerte } \\
\text { Inert }\end{array}$ & \multicolumn{2}{|c|}{1,500} & 1,500 \\
\hline Farelo de soja & 30,128 & 28,853 & TOTAL & \multirow{2}{*}{\multicolumn{2}{|c|}{100,046}} & 100,083 \\
\hline Soybean meal & & & & & & \\
\hline $\begin{array}{l}\text { Farelo de glúten de milho } \\
\text { Corn gluten meal }\end{array}$ & - & 7,941 & \multicolumn{4}{|c|}{$\begin{array}{c}\text { Composições calculadas } \\
\text { Calculated compositions }\end{array}$} \\
\hline $\begin{array}{l}\text { Óleo de soja } \\
\text { Soybean oil }\end{array}$ & 2,571 & 1,632 & $\begin{array}{l}\text { Energia metabolizável } \\
\text { Metabolizable energy }\end{array}$ & $(\mathrm{kcal} / \mathrm{kg})$ & 3.000 & 3.000 \\
\hline $\begin{array}{l}\text { Calcário } \\
\text { Limestone }\end{array}$ & 1,000 & 1,027 & Proteína bruta & $(\%)$ & 20,00 & 23,00 \\
\hline $\begin{array}{l}\text { Fosfato bicálcico } \\
\text { Dicalcium phosphate }\end{array}$ & 1,860 & 1,826 & $\begin{array}{l}\text { Crude protein } \\
\text { Cálcio }\end{array}$ & $(\%)$ & 0,960 & 0,960 \\
\hline $\begin{array}{l}\text { DL-Metionina, } 99 \% \\
\text { DL-Methionine, } 99 \%\end{array}$ & 0,285 & 0,130 & $\begin{array}{l}\text { Calcium } \\
\text { Fósforo total }\end{array}$ & $(\%)$ & 0,668 & 0,679 \\
\hline $\begin{array}{l}\text { L-Arginina, } 99 \% \\
\text { L-Arginine, } 99 \%\end{array}$ & 0,097 & - & $\begin{array}{l}\text { Total phosphorus } \\
\text { Fósforo disponível }\end{array}$ & $(\%)$ & 0,450 & 0,450 \\
\hline $\begin{array}{l}\text { Glicina } \\
\text { Glycine }\end{array}$ & 0,296 & - & $\begin{array}{l}\text { Available phosphorus } \\
\text { Sódio }\end{array}$ & $(\%)$ & 0,225 & 0,222 \\
\hline $\begin{array}{l}\text { L-Lisina } \mathrm{HCl}, 98 \% \\
\text { L-Lysine } \mathrm{HCl}, 98 \%\end{array}$ & 0,332 & 0,295 & $\begin{array}{l}\text { Sodium } \\
\text { Potássio }\end{array}$ & $(\%)$ & $\mathbf{0 , 7 3 7}$ & 0,712 \\
\hline $\begin{array}{l}\text { L-Treonina, } 98,5 \% \\
\text { L-Threonine, } 98.5 \%\end{array}$ & 0,139 & 0,007 & $\begin{array}{l}\text { Potassium } \\
\text { Cloro }\end{array}$ & $(\%)$ & 0,484 & $\mathbf{0 , 4 5 7}$ \\
\hline L-Triptofano, $99 \%$ & 0,012 & - & $\begin{array}{l}\text { Chlorine } \\
\text { Arginina digestível }\end{array}$ & $(\%)$ & 1,260 & 1,260 \\
\hline $\begin{array}{l}\text { L-Tryptophan, } 99 \% \\
\text { Sal }\end{array}$ & 0,469 & 0,460 & Digestible arginine & & & \\
\hline Salt & & & $\begin{array}{l}\text { Glicina + Serina } \\
\text { Glycine plus serine }\end{array}$ & $(\%)$ & 2,096 & 2,096 \\
\hline $\begin{array}{l}\text { Cloreto de amônia } \\
\text { Amonium cloret }\end{array}$ & 0,122 & 0,134 & $\begin{array}{l}\text { Glycine plus serine } \\
\text { Metionina }+\end{array}$ & & & \\
\hline $\begin{array}{l}\text { Cloreto colina, } 60 \% \\
\text { Choline cloret, } 60 \%\end{array}$ & 0,100 & 0,100 & $\begin{array}{l}\text { Cistina digestível } \\
\text { Digestible Meth }+ \text { Cys }\end{array}$ & $(\%)$ & 0,815 & 0,815 \\
\hline Mistura vitamínica ${ }^{1}$ & 0,100 & 0,100 & $\begin{array}{l}\text { Lisina digestível } \\
\text { Digestible lysine }\end{array}$ & $(\%)$ & 1,143 & 1,143 \\
\hline $\begin{array}{l}\text { Vitamin supplement }{ }^{1} \\
\text { Mistura mineral }^{2} \\
\text { Mineral supplement }^{2}\end{array}$ & 0,050 & 0,050 & $\begin{array}{l}\text { Treonina digestível } \\
\text { Digestible threonine }\end{array}$ & $(\%)$ & 0,766 & 0,766 \\
\hline $\begin{array}{l}\text { Mineral supplement } \\
\text { Virginamicina }^{3} \\
\text { Virginiamicin }^{3}\end{array}$ & 0,050 & 0,050 & $\begin{array}{l}\text { Triptofano digestível } \\
\text { Digestible triptophan }\end{array}$ & $(\%)$ & 0,221 & 0.221 \\
\hline $\begin{array}{l}\text { Anticoccidiano }{ }^{4} \\
\text { Anticoccidiostatic }^{4}\end{array}$ & 0,055 & 0,055 & $\begin{array}{l}\text { Balanço eletrolítico } \\
\text { Electrolyte balance }\end{array}$ & $\mathrm{mEq} / \mathrm{kg})$ & 150 & 150 \\
\hline $\begin{array}{l}{ }^{1} \text { Conteúdo (Content) vit. A - } 10 \\
\text { acid) }-12,0 \mathrm{~g} \text {; Biotina (Biotin } \\
-15.000 \text { mcg; Selênio (Selen } \\
{ }^{2} \text { Conteúdo (Content): Mn } 16,0{ }^{3} \text { Stafac }^{\circledR} 20 \text {. } \\
{ }^{4} \text { Coxistac }^{\circledR} \text { - Salinomicina (Sa } \\
{ }^{5} \text { Hidroxi Butil Tolueno. }^{2}\end{array}$ & $\begin{array}{l}0.000 \text { Ul; vit. } \\
10 \mathrm{~g} ; \text { vit. K3 } \\
-0,25 \mathrm{~g} ; \mathrm{e} \\
\mathrm{Fe}-100,0 \mathrm{~g} ; \\
\text { micin) - } 12 \% \text {. }\end{array}$ & $\begin{array}{l}000.000 \text { Ul; } \\
\text { g; Ácido fó } \\
\text { lo q. s. p. - } \\
100,0 \text { g; Cu }\end{array}$ & $\begin{array}{l}30.000 \text { Ul; vit. B1 - 2,0g } \\
\text { lic acid) - 1,0 g; Ácido n } \\
\text {; Co - } 2,0 \mathrm{~g} ; \mathrm{I}-2,0 \mathrm{~g}\end{array}$ & $\begin{array}{l}-4,0 \mathrm{~g} ; \mathrm{Ac} \\
\text { o (Nicotini } \\
\text { lo q. s. p }\end{array}$ & $\begin{array}{l}\text { antotêr } \\
\text { cid) }-50 \\
1.000 \mathrm{~g}\end{array}$ & $\begin{array}{l}\text { (Patoth } \\
\mathrm{g} \text {; vit. }\end{array}$ \\
\hline
\end{tabular}

em tubos de ensaio e, após, centrifugado, durante cinco minutos a $1.500 \mathrm{rpm}$, para separação do soro, que foi imediatamente congelado.

Posteriormente, foram feitas as análises de $\mathrm{Ca}$, de $\mathrm{P}$ e de proteína total no soro, utilizando "kits" comerciais da In Vitro Diagnóstica.

Em seguida, essa ave foi sacrificada por deslocamento cervical e os ossos do tibiotarso de ambas as pernas foram removidos. Estes ossos foram limpos de todo o tecido aderente, medidos seus comprimentos e cortados longitudinalmente, removendo-se a medula óssea com jatos de água destilada e deionizada. Após, foram desidratados com etanol e, posteriormente, desengordurados com éter de petróleo, em aparelho de Soxhlet, por 12 horas.

Os parâmetros de resistência óssea foram determinados no osso in natura, utilizando os ossos do lado direito, em prensa INSTRON- modelo 4204, 
pertencente ao Laboratório de Papel e Celulose do Departamento de Engenharia Florestal da Universidade Federal de Viçosa.

Os ossos provenientes das pernas do lado esquerdo foram calcinados em mufla, a $600^{\circ} \mathrm{C}$, para determinação dos teores de cinzas, conforme Gardiner et al. (1961).

A seguir, as cinzas foram usadas para preparo de solução mineral, pela dissolução das cinzas em solução de ácido clorídrico (1:1). O ácido foi evaporado em banho de areia por 30 minutos. $\mathrm{O}$ aquecimento em meio ácido tem a função de descomplexar os minerais.

Os teores de cálcio e de magnésio nas cinzas foram obtidos por espectrofotometria de absorção atômica, enquanto os de sódio e de potássio, por espectrofotometria de chama e o de fósforo, por colorimetria, conforme metodologias descritas por Silva (1990).

As análises estatísticas dos dados obtidos foram realizadas utilizando-se o programa SAEG - Sistema para Análises Estatísticas e Genéticas (UFV, 1997). Foi feita análise de variância, com posterior uso de regressão polinomial para cada variável estudada, além do teste de F a 5\% de probabilidade, na comparação de médias dos tratamentos para cada nível protéico estudado.

Por interesse do estudo, optou-se pelo desdobramento do BE dentro de cada nível protéico, independentemente da significância da interação.

Tabela 2 - Tratamentos constituídos pelas rações basais (20 e 23\% de proteína bruta) suplementadas com $\mathrm{NH}_{4} \mathrm{Cl}$ ou $\mathrm{K}_{2} \mathrm{CO}_{3}$

Table 2 - Treatments constituted by the basal rations (20 and $23 \%$ of crude protein) supplemented with $\mathrm{NH}_{4} \mathrm{Cl}$ or $\mathrm{K}_{2} \mathrm{CO}_{3}$

\begin{tabular}{cccccc}
\hline $\mathrm{BE}(\mathrm{mEq} / \mathrm{kg})$ & $\begin{array}{c}\text { Ração basal }(\mathrm{kg}) \\
E B(\mathrm{mEq} / \mathrm{kg})\end{array}$ & $\begin{array}{c}\text { Inerte }(\mathrm{kg}) \\
\text { Basal ration }(\mathrm{kg})\end{array}$ & $\begin{array}{c}\mathrm{NH}_{4} \mathrm{Cl}(\mathrm{kg}) \\
\mathrm{NH}_{4} \mathrm{Cl}(\mathrm{kg})\end{array}$ & $\begin{array}{c}\mathrm{K}_{2} \mathrm{CO}_{3}(\mathrm{~kg}) \\
\mathrm{K}_{2} \mathrm{CO}_{3}(\mathrm{~kg})\end{array}$ & $\begin{array}{c}\text { Total }(\mathrm{kg}) \\
\text { Total }(\mathrm{kg})\end{array}$ \\
\hline 0 & 98,5 & 0,693 & 0,807 & - & 100 \\
50 & 98,5 & 0,962 & 0,538 & - & 100 \\
100 & 98,5 & 1,231 & 0,269 & - & 100 \\
150 & 98,5 & 1,500 & - & - & 100 \\
200 & 98,5 & 1,151 & - & 0,349 & 100 \\
250 & 98,5 & 0,802 & - & 0,698 & 100 \\
300 & 98,5 & 0,453 & - & 1,047 & 100 \\
350 & 98,5 & 0,104 & - & 1,396 & 100 \\
\hline
\end{tabular}

$\mathrm{NH}_{4} \mathrm{Cl}$ - peso molecular (U.M.A.) = 53,45; pureza 99,5\% (NH ${ }_{4} \mathrm{Cl}$ - molecular weight [U.A.M.] = 53.45; purity 99.5\%). $\mathrm{K}_{2} \mathrm{CO}_{3}$ - peso molecular (U.M.A.) =138,20; pureza 99,0\% (K, $\mathrm{CO}_{3}-$ molecular weight [U.A.M.] = 138.20; purity 99.0\%). $\mathrm{BE}$ - balanço eletrolítico.

$E B$ - electrolyte balance.

Tabela 3 - Níveis de sódio, potássio e cloro obtidos em cada ração experimental Table 3 - Levels of sodium, potassium and chlorine obtained in each experimental ration

\begin{tabular}{ccccccc}
\hline $\begin{array}{c}\mathrm{BE} \\
(\mathrm{mEq} / \mathrm{kg})\end{array}$ & $\begin{array}{c}\text { \% Sódio } \\
(20 \% \mathrm{~PB})\end{array}$ & $\begin{array}{c}\text { \% Potássio } \\
(20 \% \mathrm{~PB})\end{array}$ & $\begin{array}{c}\text { \% Cloro } \\
(20 \% \mathrm{~PB})\end{array}$ & $\begin{array}{c}\text { \% Sódio } \\
(23 \% \mathrm{~PB})\end{array}$ & $\begin{array}{c}\text { \% Potássio } \\
(23 \% \mathrm{~PB})\end{array}$ & $\begin{array}{c}\text { \% Cloro } \\
(23 \% \mathrm{~PB})\end{array}$ \\
$\begin{array}{c}\text { \% Sodium }(\mathrm{mEq} / \mathrm{kg}) \\
(20 \% \mathrm{CP})\end{array}$ & $\begin{array}{c}\text { \% Potassium } \\
(20 \% \mathrm{CP})\end{array}$ & $\begin{array}{c}\text { \% Chlorine } \\
(20 \% \mathrm{CP})\end{array}$ & $\begin{array}{c}\text { \% Sodium } \\
(23 \% \mathrm{CP})\end{array}$ & $\begin{array}{c}\text { \% Potassium } \\
(23 \% \text { CP })\end{array}$ & $\begin{array}{c}\text { \% Chlorine } \\
(23 \% \text { CP })\end{array}$ \\
\hline 0 & 0,225 & 0,737 & 1,291 & 0,222 & 0,712 & 1,264 \\
50 & 0,225 & 0,737 & 1,022 & 0,222 & 0,712 & 0,995 \\
100 & 0,225 & 0,737 & 0,753 & 0,222 & 0,712 & 0,726 \\
150 & 0,225 & 0,737 & 0,484 & 0,222 & 0,712 & 0,457 \\
200 & 0,225 & 1,086 & 0,484 & 0,222 & 1,061 & 0,457 \\
250 & 0,225 & 1,435 & 0,484 & 0,222 & 1,410 & 0,457 \\
300 & 0,225 & 1,784 & 0,484 & 0,222 & 1,759 & 0,457 \\
350 & 0,225 & 2,133 & 0,484 & 0,222 & 2,108 & 0,457 \\
\hline
\end{tabular}

$\mathrm{BE}$ - balanço eletrolítico ( $E B$ - electrolyte balance).

$\mathrm{PB}$ - proteína bruta ( $C P$ - crude protein). 
O modelo estatístico utilizado foi:

$$
Y_{i j k}=\mu+N_{i}+P_{j}+N_{i} / P_{j}+E_{i j k}
$$

em que Yijk = parâmetro observado na unidade experimental k, do nível de balanço eletrolítico i, dentro do nível de proteína bruta $\mathrm{j} ; \mu=$ média geral observada; $\mathrm{N}_{\mathrm{i}}=$ efeito do balanço eletrolítico $\mathrm{i} ; \mathrm{i}=0$; 50; 100; 150; 200; 250; 300; 350; $\mathrm{P}_{\mathrm{j}}=$ efeito do nível de proteína bruta $\mathrm{j} ; \mathrm{j}=20$ e $23 \%$; $\mathrm{N}_{\mathrm{i}} / \mathrm{P}_{\mathrm{j}}=$ efeito do balanço eletrolítico i, dentro do nível de proteína bruta $\mathrm{j} ; \mathrm{E}_{\mathrm{ijk}}=$ erro aleatório associado a cada observação.

\section{Resultados e Discussão}

Teores de fósforo, cálcio e proteína total no soro sangüíneo aos 21 dias

Os diferentes níveis de BE afetaram os níveis de cálcio, fósforo e proteína total no soro sangüíneo das aves aos 21 dias de idade (Tabela 4). Entretanto, não se observou interação do $\mathrm{BE}$ com as variáveis sangüíneas avaliadas.

Houve efeito quadrático $(\mathrm{P}<0,05)$ do teor de fósforo para os níveis de $\mathrm{BE}$ das aves que consumiram ração com $20 \%$ de PB. Os frangos obtiveram menores percentuais sangüíneos desse elemento químico com $\mathrm{BE}$ na faixa de 150 a $300 \mathrm{mEq} / \mathrm{kg}$.

Em relação aos teores de cálcio plasmático, ocorreu efeito quadrático para os tratamentos com $20 \%$ de $\mathrm{PB}(\mathrm{P}<0,01)$ e $23 \%$ de $\mathrm{PB}(\mathrm{P}<0,05)$. Os menores teores de cálcio encontrados no sangue corresponderam aos valores de $\mathrm{BE}$ entre 150 e 250 $\mathrm{mEq} / \mathrm{kg}$. O excesso desses elementos (P e Ca) em aves indica alterações do equilíbrio ácido-básico, resultado de uma resposta do organismo animal que inclui ações hormonais e mecanismos respiratórios compensatórios, culminando com o ajuste renal. Segundo Davenport (1972), quando o rim compensa distúrbios do equilíbrio ácido-básico, ocorre alteração na excreção de eletrólitos, modificando os padrões eletrolítico e ácido-básico do sangue.

$\mathrm{Na}$ Tabela 5, são apresentadas as equações de regressão e os valores de mínimos percentuais plasmáticos de cálcio e de fósforo, além do nível ótimo de BE expresso em $\mathrm{mEq} / \mathrm{kg}$, obtidos por equações de regressão polinomiais.

O ótimo BE para o fósforo foi de $174 \mathrm{mEq} / \mathrm{kg}$ para as aves que receberam $20 \%$ de $\mathrm{PB}$, atingindo teor de $6,72 \mathrm{mg} / \mathrm{dL}$ de sangue. Os melhores níveis de BE para o cálcio no sangue foram de 168 e $245 \mathrm{mEq} / \mathrm{kg}$,

\begin{tabular}{|c|c|c|c|c|c|c|}
\hline \multirow{2}{*}{$\begin{array}{l}\text { Níveis de BE } \\
\quad \mathrm{mEq} / \mathrm{kg} \\
\text { EB levels } \mathrm{mEq} / \mathrm{kg}\end{array}$} & \multicolumn{2}{|c|}{$\begin{array}{c}\text { Fósforo (mg/dL) } \\
\text { Phosphorus }(m g / d L)\end{array}$} & \multicolumn{2}{|c|}{$\begin{array}{l}\text { Cálcio }(\mathrm{mg} / \mathrm{dL}) \\
\text { Calcium }(m g / d L)\end{array}$} & \multicolumn{2}{|c|}{$\begin{array}{l}\text { Proteína total }(\mathrm{mg} / \mathrm{dL}) \\
\text { Total protein }(\mathrm{mg} / \mathrm{dL})\end{array}$} \\
\hline & $20 \%$ & $23 \%$ & $20 \%$ & $23 \%$ & $20 \%$ & $23 \%$ \\
\hline 00 & 6,95 & 7,54 & 8,14 & 9,35 & 6,25 & 6,38 \\
\hline 50 & 7,44 & 7,53 & 9,39 & 8,89 & 6,30 & 6,70 \\
\hline 100 & 7,15 & 7,37 & 8,38 & 8,20 & 6,45 & 6,16 \\
\hline 150 & 6,38 & 7,42 & 7,32 & 8,24 & 6,23 & 6,02 \\
\hline 200 & 6,69 & 7,23 & 7,56 & 7,76 & 6,20 & 6,08 \\
\hline 250 & 6,92 & 6,79 & 7,89 & 7,35 & 6,29 & 6,19 \\
\hline 300 & 6,72 & 6,93 & 8,33 & 8,00 & 6,39 & 6,21 \\
\hline 350 & 7,54 & 6,98 & 9,44 & 8,04 & 6,14 & 6,49 \\
\hline $\begin{array}{l}\text { Média } \\
\text { Mean }\end{array}$ & $6,97 \mathrm{a}$ & $7,22 \mathrm{a}$ & $8,31 \mathrm{a}$ & $8,23 a$ & $6,28 \mathrm{a}$ & $6,28 \mathrm{a}$ \\
\hline $\begin{array}{l}\text { Efeito } \\
\text { Effect }\end{array}$ & $\mathrm{Q}^{*}$ & $\mathrm{~ns}$ & $\mathrm{Q}^{* *}$ & $\mathrm{Q}^{*}$ & $\mathrm{~ns}$ & $\mathrm{Q}^{*}$ \\
\hline $\mathrm{CV}(\%)$ & 9,38 & 10,91 & 6,70 & & & \\
\hline \multicolumn{7}{|c|}{$\begin{array}{l}Q^{* *} \text { efeito quadrático }(P<0,01) ; Q^{*} \text { efeito quadrático }(P<0,05) ; \text { ns não significativo; } C V=\text { coeficiente de } \\
\text { variação. } \\
Q^{* *} \text { Quadratic effect }(P<.01) ; Q^{*} \text { Quadratic effect }(P<.05) ; \text { ns not significant; } C V=\text { coefficient of variation. } \\
\text { Médias dos tratamentos seguidas pela mesma letra não diferem }(P<0,05) \text { estatisticamente pelo teste } F \text {. } \\
\text { Treatments means followed by the same letter do not differ }(P<.05) \text { by } F \text { test; } C V=\text { coefficient of variation. }\end{array}$} \\
\hline
\end{tabular}

R. Bras. Zootec., v.33, n.6, p.1520-1530, 2004 
atingindo teores de 6,37 e $7,71 \mathrm{mg} / \mathrm{dL}$, para as aves que receberam rações com 20 e $23 \%$ de $\mathrm{PB}$, respectivamente. Os valores médios dos níveis de fósforo no sangue $(6,97$ e 7,22 mg/dL) encontram-se acima dos citados por Scott et al. (1982), de 3,5 a $4,5 \mathrm{mg} / \mathrm{dL}$. Entretanto, estão de acordo com os encontrados por Freitas (2001) na maioria dos tratamentos estudados, ao avaliar diferentes níveis protéicos (19 a $25 \%$ de PB), em pintos de corte aos 21 dias de idade.

Os valores médios obtidos para o cálcio sérico foram de 8,31 e 8,23 mg/dL. Swenson (1996) afirma que na maioria das espécies domésticas o soro sangüíneo contém 9 a $11 \mathrm{mg} / \mathrm{dL}$ de cálcio, à exceção das galinhas poedeiras, que apresentam elevados teores séricos durante a vida produtiva, em função da postura.

Os níveis protéicos estudados não influenciaram os valores de BE para os minerais avaliados. No entanto, o excesso de cloro ou potássio influenciou o BE. Os tratamentos com os menores e os maiores valores de BE apresentaram as maiores concentrações de fósforo e de cálcio no sangue, que podem representar maior mobilização óssea desses minerais por ação hormonal, com a finalidade de disponibilizar mais eletrólitos no sangue para serem utilizados por mecanismos compensatórios de regulação no organismo das aves.

Em relação às proteínas no soro sangüíneo das aves, foi observado efeito quadrático $(\mathrm{P}<0,05)$ do teor de proteína total para os valores de BE das aves que consumiram $23 \%$ de PB. As aves obtiveram menores percentuais sangüíneos com balanços na faixa de 100 a $300 \mathrm{mEq} / \mathrm{kg}$, o que pode ser explicado pela função exercida pelas proteínas plasmáticas de ajudar a manter a pressão coloidosmótica do plasma. Swenson (1996) afirma que hipoproteinemia freqüentemente está associada ao edema, pois a pressão osmótica produzida por essas proteínas opõe-se à pressão hidrostática do sangue nos capilares e, dessa forma, evita o excesso de passagem de água para os tecidos em condições orgânicas consideradas normais.

Assim como ocorreu com o cálcio e o fósforo no sangue, os tratamentos com os menores e os maiores valores de BE apresentaram maiores concentrações de proteínas plasmáticas. Isso pode ser interpretado como uma necessidade do organismo das aves em manter uma pressão osmótica elevada tanto em acidose quanto em alcalose metabólica, a fim de facilitar a homeostasia das mesmas por mecanismos compensatórios de regulação, particularmente por via renal.

Constam, na Tabela 5, as equações de regressão e os valores de mínimos percentuais protéicos no plasma, além do nível ótimo de BE expresso em mEq/ $\mathrm{kg}$, obtidos por equações de regressão polinomiais. $\mathrm{O}$ ótimo BE obtido foi de $189 \mathrm{mEq} / \mathrm{kg}$ para as aves que receberam $23 \%$ de $\mathrm{PB}$, atingindo teor de $6,11 \mathrm{mg} / \mathrm{dL}$ de sangue. Os valores médios dos níveis de proteína total no sangue $(6,28 \mathrm{mg} / \mathrm{dL})$ encontram-se acima dos citados por Swenson (1996), de 3,6 mg/dL. É possível que aves das atuais marcas comerciais de frangos de corte apresentem níveis mais elevados de proteína no sangue, em função de seu acelerado metabolismo em relação ao de aves de crescimento corporal inicial lento. Segundo Guyton (1997), se as concentrações de proteínas plasmáticas estiverem diminuídas, o fluido não é atraído de volta ao compartimento intravascular, acumulando-se nos espaços do tecido extravascular, caracterizando condição conhecida

Tabela 5 - Equações de balanço eletrolítico (BE) para os parâmetros sangüíneos de pintos de corte aos 21 dias Table 5 - Electrolyte balance (EB) equations for blood parameters of broiler chicks at 21 days of age

\begin{tabular}{cccccc}
\hline $\begin{array}{c}\text { Parâmetro } \\
\text { Parameter }\end{array}$ & $\begin{array}{c}\text { Proteína } \\
\text { Protein }\end{array}$ & $\begin{array}{c}\text { Equação } \\
\text { Equation }\end{array}$ & $\mathrm{R}^{2}$ & $\begin{array}{c}\text { Mín } \\
\mathrm{BE}(\mathrm{mEq} / \mathrm{kg}) \\
E B(\mathrm{mEq} / \mathrm{kg})\end{array}$ \\
\hline $\mathrm{P}$ & $20 \%$ & $\hat{\mathrm{Y}}=7,30-0,0066091^{\mathrm{ns}} \mathrm{X}+0,0000189919^{*} \mathrm{X}^{2}$ & 0,35 & 6,72 & 174,00 \\
$\mathrm{Ca}$ & $20 \%$ & $\hat{\mathrm{Y}}=8,93-0,0140635^{\mathrm{ns}} \mathrm{X}+0,0000419242^{* *} \mathrm{X}^{2}$ & 0,45 & 7,75 & 167,72 \\
& $23 \%$ & $\hat{\mathrm{Y}}=9,41-0,0138844^{* *} \mathrm{X}+0,0000283727^{*} \mathrm{X}^{2}$ & 0,90 & 7,71 & 244,68 \\
Ptn & $23 \%$ & $\hat{\mathrm{Y}}=6,57-0,0049138^{\mathrm{ns}} \mathrm{X}+0,0000129919^{*} \mathrm{X}^{2}$ & 0,52 & 6,10 & 189,11 \\
\hline
\end{tabular}

Ptn $=$ proteínas plasmáticas totais aos 21 dias.

PTN = total plasma protein at 21 days.

Efeito significativo $(P<0,05) ;{ }^{* \star}$ efeito significativo $(P<0,01)$; ns não-significativo.

* Significant effect $(P<.05) ;{ }^{* *}$ Significant effect $(P<.01)$; ${ }^{\text {*s }}$ not significant.

\section{R. Bras. Zootec., v.33, n.6, p.1520-1530, 2004}


como edema. Pode-se, então, supor que o intenso metabolismo das aves das atuais marcas comerciais levou a um aumento dos níveis plasmáticos de proteína, importante para o ajuste renal visando manter o equilíbrio ácido-básico.

Observa-se, na Tabela 6, que os diferentes níveis de BE não afetaram a resistência óssea.

Os resultados do presente experimento corroboram as observações feitas por Rostagno et al. (1996) e Brugalli et al. (1999), em que a exigência nutricional para otimizar o desempenho das aves é inferior à exigência para maximizar a resistência óssea. Narváez et al. (1997), ao estudarem a exigência de cálcio, encontraram que, dentre os parâmetros avaliados, a resistência óssea foi a característica que teve a maior exigência de cálcio. Segundo Zollitsch et al. (1996), a mobilização óssea para atender às necessidades metabólicas de íons é um processo normal, e a perda óssea somente comprometerá a resistência quando houver deficiência prolongada.

No presente trabalho a resistência à quebra não foi influenciada pelas aves que receberam dietas com baixos BE (acidose metabólica). Segundo Veltman \& Jensen (1979), aves em acidose metabólica perdem em $50 \%$ a capacidade de produziro 1,25 dihidroxicolecalciferol, podendo apresentar alterações no desenvolvimento ósseo. Silva (2000), em ensaio com pintos de 1 a 14 dias recebendo dieta purificada, obteve máxima resistência óssea com suplementação de níveis elevados de vitamina $\mathrm{D}_{3}$ nas dietas, concordando com os autores supracitados.

A resistência à quebra ao tibiotarso apresentou coeficiente de variação bastante elevado, comparado aos das demais variáveis, o que foi verificado também por Brugalli et al. (1999), que obteve o valor de 19,73 para esse mesmo osso, e por Lima (1995), cujo coeficiente em seu experimento foi de 22,24 para o fêmur. Crenshaw et al. (1981) sugerem que seja considerada, além da força, a área sobre a qual é aplicada, pois essa técnica contribui para diminuição do coeficiente de variação em experimentos para avaliação da resistência óssea.

Os diferentes níveis de BE afetaram o teor de cálcio no tibiotarso das aves que consumiram ração com 23\% de PB e o teor de potássio nas aves cuja ração possuía $20 \%$ de PB (Tabela 7). Não se observou interação do BE com o teor de cinzas ou com qualquer mineral avaliado. Embora não tenha ocorrido efeito significativo, verifica-se que os percentuais mais altos de cinzas ocorreram com nível de BE acima de
$150 \mathrm{mEq} / \mathrm{kg}$ e os percentuais mais altos de fósforo, no intervalo de 100 a $250 \mathrm{mEq} / \mathrm{kg}$. Em relação ao sódio e ao magnésio, nenhuma inferência pode ser feita com os resultados obtidos.

Foram observados efeitos quadráticos dos níveis de $\mathrm{BE}$ para o cálcio $(\mathrm{P}<0,01)$ e o potássio $(\mathrm{P}<0,10)$ para os tratamentos com 23 e $20 \%$ de $P B$, respectivamente. Na Tabela 8 , são apresentadas as equações de regressão e os valores de máximo ganho de peso e de consumo de ração, além do nível ótimo de balanço eletrolítico expresso em $\mathrm{mEq} / \mathrm{kg}$, obtidos por equações de regressão polinomiais.

O melhor valor de BE para a deposição de cálcio no tibiotarso foi de $132 \mathrm{mEq} / \mathrm{kg}$ para a ração com $23 \%$ de PB, culminando com teor ósseo de $34,33 \%$ do mineral. Vargas Jr. (2002), ao trabalharem com aves de reposição leves e semipesadas de 0 a 6 semanas de idade, verificaram aumento do cálcio e do fósforo no osso com o incremento dos níveis de cálcio e de fósforo na ração somente para aves semipesadas, que pode estar relacionado ao ritmo maior de crescimento em relação às aves leves.

Tabela 6 - Efeito de balanços eletrolíticos (BE) para 20 e $23 \%$ de proteína sobre a resistência óssea Table 6 - Electrolyte balances (EB) effect for 20 and 23\% of protein on broiler chicks performance on the breaking strength

\begin{tabular}{|c|c|c|}
\hline \multirow{2}{*}{$\begin{array}{l}\text { Níveis de BE } \\
(\mathrm{mEq} / \mathrm{kg}) \\
\text { EB levels } \\
(\mathrm{mEq} / \mathrm{kg})\end{array}$} & \multicolumn{2}{|c|}{$\begin{array}{c}\text { Resistência óssea }(\mathrm{kgf} / \mathrm{mm}) \\
\text { Breaking strenght }(\mathrm{kgf} / \mathrm{mm})\end{array}$} \\
\hline & $20 \%$ & $23 \%$ \\
\hline 00 & 21,74 & 22,33 \\
\hline 50 & 22,60 & 25,86 \\
\hline 100 & 22,56 & 22,17 \\
\hline 150 & 23,70 & 24,22 \\
\hline 200 & 24,47 & 23,06 \\
\hline 250 & 21,67 & 26,12 \\
\hline 300 & 22,34 & 21,63 \\
\hline 350 & 22,00 & 22,89 \\
\hline $\begin{array}{l}\text { Média } \\
\text { Mean }\end{array}$ & $22,63^{a}$ & $23,53^{a}$ \\
\hline $\begin{array}{l}\text { Efeito } \\
\text { Effect }\end{array}$ & $\mathrm{ns}$ & $\mathrm{ns}$ \\
\hline $\mathrm{CV}(\%)$ & 13,29 & \\
\hline \multicolumn{3}{|c|}{$\begin{array}{l}\text { ns Não-significativo; CV = coeficiente de variação. } \\
\text { ns Not significant; } C V=\text { coefficient of variation. } \\
\text { Médias dos tratamentos seguidas pela mesma letra não diferem } \\
\text { estatisticamente pelo teste } F(P<0,05) \text {. } \\
\text { Treatments means followed by the sameletterdo not differ by } F \text { test }(P<.05) \text {; } \\
C V=\text { coefficientof variation. }\end{array}$} \\
\hline
\end{tabular}


Tabela 7 - Efeito de balanços eletrolíticos (BE) para 20 e $23 \%$ de proteína sobre os teores de cinzas e minerais no tibiotarso

Table 7 - Electrolyte balances (EB) effect for 20 and $23 \%$ of protein on bone ash and minerals

\begin{tabular}{|c|c|c|c|c|c|c|}
\hline \multirow{2}{*}{$\begin{array}{c}\text { Níveis de } \mathrm{BE}(\mathrm{mEq} / \mathrm{kg}) \\
\text { EB levels }(m E q / \mathrm{kg})\end{array}$} & \multicolumn{2}{|c|}{$\begin{array}{c}\text { Cinzas (\%) } \\
\text { Ash (\%) }\end{array}$} & \multicolumn{2}{|c|}{$\begin{array}{l}\text { Cálcio (\%) } \\
\text { Calcium (\%) }\end{array}$} & \multicolumn{2}{|c|}{$\begin{array}{c}\text { Fósforo (\%) } \\
\text { Phosphorus (\%) }\end{array}$} \\
\hline & $20 \%$ & $23 \%$ & $20 \%$ & $23 \%$ & $20 \%$ & $23 \%$ \\
\hline 00 & 26,11 & 27,20 & 33,56 & 32,77 & 17,95 & 18,34 \\
\hline 50 & 25,86 & 27,12 & 32,95 & 34,56 & 17,71 & 18,52 \\
\hline 100 & 26,88 & 26,75 & 33,68 & 34,03 & 18,98 & 18,67 \\
\hline 150 & 27,37 & 27,43 & 33,85 & 34,41 & 18,67 & 18,59 \\
\hline 200 & 27,51 & 27,96 & 34,86 & 35,16 & 18,24 & 18,56 \\
\hline 250 & 27,67 & 28,10 & 34,86 & 32,18 & 18,22 & 17,06 \\
\hline 300 & 27,06 & 26,76 & 32,93 & 32,02 & 17,94 & 18,20 \\
\hline 350 & 27,95 & 28,56 & 33,86 & 32,05 & 17,73 & 17,67 \\
\hline $\begin{array}{l}\text { Média } \\
\text { Mean }\end{array}$ & $27,05^{\mathrm{a}}$ & $27,48^{\mathrm{a}}$ & $33,82^{\mathrm{a}}$ & $33,40^{\mathrm{a}}$ & $18,18^{\mathrm{a}}$ & $18,20^{\mathrm{a}}$ \\
\hline & \multicolumn{5}{|c|}{ Effect } & $\mathrm{ns}$ \\
\hline $\mathrm{CV}(\%)$ & 11,42 & 5,53 & 7,29 & & & \\
\hline $\begin{array}{c}\text { Níveis de } \mathrm{BE} \mathrm{mEq} / \mathrm{kg} \\
\text { EB levels }(\mathrm{mEq} / \mathrm{kg})\end{array}$ & Potassium (\%) & Potássio (\%) & \multicolumn{2}{|c|}{ Sódio (\%) } & \multicolumn{2}{|c|}{ Magnésio (\%) } \\
\hline & $20 \%$ & $23 \%$ & $20 \%$ & $23 \%$ & $20 \%$ & $23 \%$ \\
\hline 00 & 1,45 & 1,44 & 1,52 & 1,6 & 0,81 & 0,82 \\
\hline 50 & 1,45 & 1,33 & 1,62 & 1,44 & 0,81 & 0,76 \\
\hline 100 & 1,37 & 1,35 & 1,52 & 1,55 & 0,85 & 0,84 \\
\hline 150 & 1,30 & 1,36 & 1,53 & 1,47 & 0,86 & 0,81 \\
\hline 200 & 1,26 & 1,29 & 1,45 & 1,46 & 0,82 & 0,85 \\
\hline 250 & 1,26 & 1,28 & 1,58 & 1,4 & 0,8 & 0,78 \\
\hline 300 & 1,21 & 1,28 & 1,4 & 1,53 & 0,8 & 0,78 \\
\hline 350 & 1,48 & 1,28 & 1,71 & 1,53 & 0,87 & 0,92 \\
\hline $\begin{array}{l}\text { Média } \\
\text { Mean }\end{array}$ & $1,35^{\mathrm{a}}$ & $1,33^{\mathrm{a}}$ & $1,54^{\mathrm{a}}$ & $1,50^{\mathrm{a}}$ & $0,82^{\mathrm{a}}$ & 0,82 \\
\hline $\begin{array}{l}\text { Efeito } \\
\text { Effect }\end{array}$ & $\mathrm{Q}^{\#}$ & $\mathrm{~ns}$ & $\mathrm{~ns}$ & $\mathrm{~ns}$ & $\mathrm{~ns}$ & $\mathrm{~ns}$ \\
\hline $\mathrm{CV}(\%)$ & 20,20 & 14,40 & 13,82 & & & \\
\hline
\end{tabular}

Tabela 8 - Equações de balanço eletrolítico para os parâmetros ósseos Table 8 - Electrolyte balance equations for bone parameters

\begin{tabular}{cccccc}
\hline $\begin{array}{c}\text { Parâmetro } \\
\text { Parameter }\end{array}$ & $\begin{array}{c}\text { Proteína } \\
\text { Protein }\end{array}$ & $\begin{array}{c}\text { Equação } \\
\text { Equation }\end{array}$ & $\mathrm{R}^{2}$ & $\begin{array}{c}\text { Máx/ } \\
\text { Mín }\end{array}$ & $\begin{array}{c}\mathrm{BEo}(\mathrm{mEq} / \mathrm{kg}) \\
E B(\mathrm{mEq} / \mathrm{kg})\end{array}$ \\
\hline $\mathrm{Ca}$ & $23 \%$ & $\hat{\mathrm{Y}}=33,25+0,016405^{* *} \mathrm{X}-0,000062178^{* *} \mathrm{X}^{2}$ & 0,60 & 34,33 & 131,92 \\
$\mathrm{~K}$ & $20 \%$ & $\hat{\mathrm{Y}}=1,51-0,002338^{\mathrm{ns}} \mathrm{X}+0,00000575^{\#} \mathrm{X}^{2}$ & 0,62 & 1,27 & 203,31 \\
\hline
\end{tabular}

${ }^{* *}$ Efeito significativo $(P<0,01)$; * efeito significativo $(P<0,05)$; \# efeito significativo $(P<0,10)$; ns não-significativo.

** Significant effect $(P<.01)$; " Significant effect $(P<.05)$; \# Significant effect $(P<.10)$; ${ }^{*}$ not significant effect. 
O ótimo BE obtido para o teor de potássio no tibiotarso foi de $203 \mathrm{mEq} / \mathrm{kg}$ para a ração com $20 \%$ de PB, culminando com percentual ósseo de $1,27 \%$ do mineral. Os resultados diferem dos encontrados por Scott et al. (1982), que observaram maior armazenamento de $\mathrm{Na}$ e K nos ossos, quando ingeridos em excesso ou quando as aves se encontram em estado de alcalose metabólica, porém corroboram os achados de Freitas (2002), que não observou maior teor de potássio nos ossos das aves que receberam maior suplementação desse mineral na ração.

A inter-relação entre os minerais é assunto bastante controverso e alguns trabalhos sugerem que o efeito do BE seja dependente do tipo de cátion manipulado na dieta (Rondon et al., 1999; Murakami, 1999; Jonnson \& Karunajeewa, 1985). Halley et al. (1987) afirmaram que é possível aumentar ou diminuir a incidência de discondroplasia tibial (DT) pela manipulação da relação cátion:ânion da dieta. Esses autores observaram alta correlação entre a DT e o desequilíbrio ácido-base, indicando o efeito da manipulação do conteúdo mineral da dieta sobre a capacidade tampão do sangue, o que pode afetar funções como a mineralização dos ossos.

\section{Conclusões}

Os ótimos valores de $\mathrm{BE}$ estimados para as variáveis sangüíneas aos 21 dias variaram de 168 a $245 \mathrm{mEq} / \mathrm{kg}$. Para o cálcio no tibiotarso, o BE mais adequado foi de $132 \mathrm{mEq} / \mathrm{kg}$. Entretanto, respeitando as respostas biológicas, obtidas pelas aves para os parâmetros sangüíneos e ósseos, recomenda-se valores de BE na faixa de 150 a $200 \mathrm{mEq} / \mathrm{kg}$. A resistência óssea não foi influenciada pelos níveis de $\mathrm{BE}$ das rações.

\section{Literatura Citada}

BRUGALLI, I.; SILVA, D.J.; ALBINO, L.F.T. et al. Exigência de fósforo disponível e efeito da granulometria na biodisponibilidade de fósforo da farinha de carne e ossos para pintos de corte. Revista Brasileira de Zootecnia, v.28, n.6, p.1288-1296, 1999.

CRENSHAW, T.D.; PEO, E.R.; LEWIS, A.J. et al. Bone strength as a trait for assessing mineralization in swine: a critical review of techniques involved. Journal of Animal Science, v.53, n.3, p.827-835, 1981.

DARI, R.L. Eletrólitos para aves. Boletim técnico para funcionários e clientes da Nutron Alimentos: Ave news, out. 2002. 8p.
DAVENPORT, H.W. ABC do equilíbrio ácido-básico do sangue. 2.ed. São Paulo: Edart, 1972. 84p.

EDWARDS Jr., H.M. Nutritional factors and leg disorders. In: WHITEHEAD, C.C. (Ed.) Bone biology and skeletal disorders in poultry. Abingdon: Carfax Publishing Co., 1992. p.167-193.

FREITAS, H.T. Efeitos de composição das dietas com diferentes níveis de proteínas e de nutrientes sobre o desempenho e as características ósseas de pintos de corte. Viçosa, MG: Universidade Federal de Viçosa, 2002. 144p. Tese (Doutorado em Zootecnia) - Universidade Federal de Viçosa, 2002.

GARDINER, E.E.; TOGLER, J.C.; PARKER, H.E. Interelationships between magnesium and fluoride in chicks. Journal Nutrition, v.75, p.270-274, 1961.

GONZÁLES, F.H.D.; SILVA, S.C. Introdução à bioquímica clínica veterinária. 1999. Disponível em: <http:// www.ufrgs.br/favet/bioquimica/

GUYTON, A.C. Tratado de fisiologia médica. 11.ed. Rio de Janeiro: Guanabara Koogan, 1997. 1014p.

HALLEY, J.T.; NELSON, T.S.; KIRBY, L.K. et al. Effect of altering dietary mineral balance on growth, leg abnormalities, and blood base excess in broiler chicks. Poultry Science, v.66, p.1684-1692, 1987.

HEANEY, R.P. Excess dietary protein may not adversely affect bone. Issues and Opinion in Nutrition, v.128, p.10541057, 1998.

JOHNSON, R.J.; KARUNAJEEWA, H. The effects of dietary minerals and electrolytes on the growth and physiology of the young chick. Journal Nutrition, v.115, p.1680-1690, 1985.

LIMA, I.L. Disponibilidade de fósforo e de flúor de alguns alimentos e exigência nutricional de fósforo para frangos de corte. Viçosa, MG: Universidade Federal de Viçosa, 1995. 121p. Tese (Doutorado em Zootecnia) - Universidade Federal de Viçosa, 1995.

MACARI, M.; FURLAN, R.L.; GONZALEZ, E. Fisiologia aviária aplicada a frangos de corte. Jaboticabal: Universidade Estadual Paulista, 1994.

McDOWELL, L.R. Calcium and phosphorus - minerals in animal and human nutrition. San Diego: Academic Press, 1992. p.26-77.

MONGIN, P. Recent advances in dietary anion-cation balance: application in poultry. Procedure Nutrition Society, v.40, p.285-294, 1981.

MONGIN, P.; SAUVEUR, B. Interrelationships between mineral nutrition, acid-base, growth and cartilage abnormalities. Proceedings Poultry Science, n.12, p.235-247, 1977.

MURAKAMI, A.E. Balanço eletrolítico da dieta e sua influência sobre o desenvolvimento dos ossos de frangos. In: CONFERÊNCIA APINCO DE CIÊNCIA E TECNOLOGIA AVÍCOLAS, 2000, Campinas. Palestras... Campinas: Fundação APINCO de Ciência e Tecnologia Avícolas, 2000. p.33-61.

MURAKAMI, A.E.; RONDÓN, E.O.O.; FURLAN, A.C. et al. Sodium and chloride nutritional requirements for growing broiler chickens ( 22 to 42 days of age). In: POULTRY SCIENCE ASSOCIATION, 88., 1999, Arkansas. Annual meeting... Arkansas: Poultry Science Association, 1999. p.63-64.

NARVÁEZ, W.V.; ROSTAGNO, H.S.; SOARES, P.R. et al. Níveis de cálcio para poedeiras comerciais leves de 46 a 62 semanas de idade. In: REUNIÃO ANUAL DA SOCIEDADE 
BRASILEIRA DE ZOOTECNIA, 34., 1997, Juiz de Fora. Anais... Juiz de Fora: Sociedade Brasileira de Zootecnia, 1997. p.27.

PATIENCE, J.F. A review of the role acid-base balance in amino acid nutrition. Journal Animal Science, v.68, p.398-408, 1990.

RONDÓN, E.O.O.; MURAKAMI, A.E.; MARTINS, E.N. et al. Sodium and chloride nutritional requirements for young broiler chickens ( 1 to 21 days of age). In: POULTRY SCIENCE ASSOCIATION, 88., 1999, Arkansas. Annual meeting... Arkansas: Poultry Science Association, 1999. p.63.

ROSS, M.H.; ROWRELL, L.J. Histologia - texto e atlas. 2.ed. São Paulo: Média Panamericana, 1993. 779p.

ROSTAGNO, H.S. Tabelas brasileiras para aves e suínos: Composição de alimentos e exigências nutricionais. Viçosa, MG: Universidade Federal de Viçosa, 2000. 141p.

ROSTAGNO, H.S.; BARBARINO JR., P.; BARBOZA, W.A. Exigências nutricionais de aves determinadas no Brasil. In: SIMPÓSIO INTERNACIONAL SOBRE EXIGÊNCIAS NUTRICIONAIS DE AVES E SUÍNOS, 1996, Viçosa, MG. Resumos... Viçosa, MG: Universidade Federal de Viçosa, 1996. p.361-388.

SAUVEUR, B. Dietary factors as causes of leg abnormalities in poultry - A Review. World's Poultry Science Journal, v.40, p.195-206, 1984.

SCOTT, M.L.; NESHEIM, M.C.; YOUNG, R.J. Essential inorganic elements - nutrition of the chicken. 3.ed. New York: M.L Scott Associates, 1982, p.287-304.

SILVA, D.J. Análises de alimentos: métodos químicos e biológicos. 2.ed. Viçosa, MG: Universidade Federal de Viçosa, 1990. 165 p.

SILVA, F.A. Efeitos dos níveis do ácido L-glutâmico e da vitamina $D_{3}$ no desempenho e anomalias ósseas de pintos de corte. Viçosa, MG: Universidade Federal de Viçosa, 2000. 147p. Tese (Doutorado em Zootecnia) Universidade Federal de Viçosa, 2000.
SUMMERS, J.D.; SHEN, H.; LESSON, S. et al. Influence of vitamin deficiency and level of dietary protein on the incidence of leg problems in broiler chicks. Poultry Science, v.63, p.1115-1121, 1984.

SWENSON, M.J. DUKES - Fisiologia dos animais domésticos. 11.ed. Rio de Janeiro: Guanabara, 1996. 856p.

TARDIN, A.C. Visão nutricional dos problemas locomotores em frangos de Corte. In: CONFERÊNCIA APINCO DE CIÊNCIA E TECNOLOGIA AVÍCOLAS, 1995, Campinas. Palestras... Campinas: Fundação APINCO de Ciência e Tecnologia Avícolas, 1995. p.71-83.

TEETER, R.G. The electrolyte: acid-base connection. Feed mix, v.5, n.4, p.32-34, 1997.

VARGAS Jr., J.G. Exigências de cálcio e de fósforo disponível para aves de reposição leves e semipesadas. Viçosa, MG: Universidade Federal de Viçosa, 2002. 113p. Tese (Doutorado em Zootecnia) - Universidade Federal de Viçosa, 2002.

VELTMAN, J.; JENSEN, L. Dietary studies on incidence of tibial dyscondroplasia in broiler chicks. Poultry Science, v.58, p.1026-1027, 1979.

ZOOLLITSCH, W.; ZHIQIANG, C.; PEGURI, A. et al. Nutrient requirements of laying hens. In: SIMPÓSIO INTERNACIONAL SOBRE EXIGÊNCIAS NUTRICIONAIS DE AVES E SUÍNOS, 1996, Viçosa, MG. Resumos... Viçosa, MG, 1996. p.109-159.

Recebido em: 18/06/03

Aceito em: 04/02/03 